\title{
Stabilization of galvanic sludge by microwave pre-treated pyrolysis
}

\author{
H. O. Sadikoglu ${ }^{1} \cdot$ A. Ongen ${ }^{1}$
}

Received: 14 August 2015/Revised: 6 October 2015/Accepted: 30 November 2015/Published online: 14 December 2015

(C) Islamic Azad University (IAU) 2015

\begin{abstract}
The study was aimed examine the effect of microwave preheated pyrolysis on the characteristics of volatile metal compounds. In order to monitor the behavior of volatile metals, samples were preheated with microwave oven in varying energy ranges and process durations. In order to determine optimum conditions, 360-, 600- and 900-W microwave power and 3-, 5- and 10-min microwave irradiation were used. Chemical analyses of samples were carried out both before and after experiments by X-ray fluorescence. Pyrolysis experiments were performed in a laboratory-scale fixed-bed updraft stainless steel reactor in the presence of $1 \mathrm{~L} \mathrm{~min}{ }^{-1} \mathrm{~N}_{2}$ gas. Content of synthetic gas product obtained via pyrolysis was analyzed by a continuous gas analyzer. Microwave preheated pyrolysis resulted an increase in the weight percentage of calcium oxide, iron(III) oxide, and chromium(III) oxide in galvanic sludge. Similar changes were determined for most of the samples at $600 \mathrm{~W}$ and $5 \mathrm{~min}$ of microwave preheated pyrolysis. In this point, the weight percentage of calcium oxide, iron(III) oxide, and chromium(III) oxide were measured as $22.47,16.93$, and $5.63 \mathrm{wt} \%$ which were 19.86 , 10.89 , and $3.03 \mathrm{wt} \%$ after single pyrolysis. It is concluded that, future analysis are needed to increase the efficiency of stabilization by microwave preheated pyrolysis.
\end{abstract}

Keywords Thermochemical process .

Metal stabilization · Irradiation ·

Waste management

A. Ongen

aongen@istanbul.edu.tr

1 Department of Environmental Engineering, Faculty of Engineering, Istanbul University, 34320 Avcilar, Istanbul, Turkey

\section{Introduction}

With the aim of preventing the sludge caused by wastewater treatment systems and the probable damage of these systems to human and environment, various management mechanisms have been practiced (Collivignarelli et al. 2015; Garrido-Baserba et al. 2015; Ibanez et al. 2015; Moon et al. 2015; Pavlik et al. 2015; Semiyaga et al. 2015; Yang et al. 2015). Being practiced in spite of the negative aspects of the management of wastewater sludge, storage is giving its place to the methods of waste stabilization and safe recycling/recovery with respect to the European Union regulations (Cieslik et al. 2015). In case of the management of wastewater treatment sludge via thermal processes, appearance of volatile metal forms is an important problem that poses a risk by causing air pollution.

In pyrolysis, inert environment or in the atmosphere, biomass/waste means the thermal degradation of material. During the pyrolysis of biomass/waste, several different and quite complex reactions take place as being serial and parallel. These complex reactions can be mentioned as the raffination or elimination of fuel into by-products (Iwasaki 2003). The products acquired from the pyrolysis process are divided into two as being primary products and byproducts. The acquired products contain high quality and highly valued fuel and chemical compounds. Primary products might be solid-rich in carbon-liquid or gaseous. Primary products can be used directly as well as they can be used by being transformed into by-products through chemical treatments. By-products are high-quality fuel and valuable chemical compounds (Efika et al. 2015; Chen et al. 2015).

In literature, there is no study related to the control of the volatile metal content of real treatment sludge, resulted from galvanic technical systems, with microwave 
preheated pyrolysis approach. However, microwave-assisted pyrolysis studies are applied to many different waste types (Mushtaq et al. 2014). It is suggested that the electromagnetic microwaves can energize, mitigate, and assist the chemical binding of dipolar molecules and metal ions within a solid structure (Hui et al. 2008). In a study that analyzes the fast microwave-assisted pyrolysis of domestic sewage sludge, it is reported that the maximum biofuel production is achieved at $550{ }^{\circ} \mathrm{C}$ when thermal crack occurs as an endothermic reaction, and the remained solid material can be used as fertilizer (Xie et al. 2014). There are some studies related to acquisition of utility models from the organic content of waste (Yu et al. 2014; Deng et al. 2014; Dai et al. 2013; Wub et al. 2015). However, the studies on the management of metals/heavy metals in the waste are limited. In a study conducted with worn out tires, the content of the char acquired from microwave-assisted pyrolysis is analyzed. It is found out that there are amorphous carbon and inorganic carbon types in the acquired char, which stem from the production of tire. Characteristics of carbon obtained from microwave-assisted pyrolysis are intermediate between anthracite and bitumen (Undri et al. 2013).

As a different waste type, the management of automotive shredder residue or commonly called "car fluff" wastes is generally quite troublesome and complicated because of the various materials they include. Some researchers have used microwave-assisted pyrolysis and gasification processes with the aim of management of these wastes. In their study, Donaj et al. (2010) have applied a two-stage system by using microwave pyrolysis and gasification processes together. Transformation of pyrolysis products has been observed through the use of steam at $950{ }^{\circ} \mathrm{C}$ in the gasification stage. In the specified operating instructions, it has been observed that the rate of transformation is $99 \%$ for liquid form, and $45-55 \%$ for the solid forms. In another study presented in 2011, the same researcher group conducted a similar study by using two different gasification agents on different temperatures $\left(950,850\right.$, and $\left.760{ }^{\circ} \mathrm{C}\right)$. It was observed that with the increase in heat, char transformation rate decreased for both agents. In addition, it was reported that this bizarre char action might be resulted from the ash, especially alkali metal contents. While the negative effects of the fuel characteristic on product transformation process were discussed, it was indicated that through limiting the interaction of the oxidation agent with carbon, fuel could prevent especially the char activity of metal forms (Donaj et al. 2011).

Microwave ( $\mathrm{Mw})$ pyrolysis is also used to immobilize the metal ions on solid surfaces. By this means, heavy metals are immobilized on an active surface, and their transition into an aquatic environment is limited. In a study conducted with this aim, the effects of microwave power, irradiation time, and water content of activated carbon on process were analyzed. The behaviors of ionic forms were monitored through toxicity characteristic leaching procedure (TCLP) experiment. In the samples of dry activated carbon, which were subjected to microwave with $750 \mathrm{~W}$ and for $10 \mathrm{~min}$, immobilization was observed. In the study, it was reported that the mentioned system could be applied to different metal ions such as $\mathrm{Cu}^{2+}, \mathrm{Zn}^{2+}$, and $\mathrm{Pb}^{2+}$ (Liu et al. 2013). In another study, the stabilization of copper ions within the heavy metal content sludge was studied. It was indicated that microwave heating caused molar change on a negligible level; aluminum reinforcement positively affects the conclusion in the stabilization; and with the increase in microwave power and operation time, stabilization also increased. It was reported that before reaching an elevated temperature, the moisture removed, and therefore, the reaction of copper and aluminum was a solid-phase reaction. It was also presented that in an inert atmosphere where exothermic reaction of organic material was prevented, reactions occurred in a more productive way (Hsieh et al. 2007). Chen et al. (2005) studied on a development of a microwave process to stabilize copper ions in the sludge to replace the use of traditional solidification. With this aim, sludge, both sludge and metal of which were extracted, was used. In the study where microwave radiation time and additional reagents were analyzed with the aim of management of this sludge, which is considered as hazardous waste, it was stated that contrary to the previous study, microwave radiation caused mass loss. It was determined that depending upon the structure of the sludge, efficiency of stabilization differed, and, in some cases, acid-extracted sludge showed higher stabilization. It was reported that $\mathrm{Na}_{2} \mathrm{CO}_{3}$ and $\mathrm{Na}_{2} \mathrm{SiO}_{3}$, as being separators, had no positive effect on the process; however, in iron-added systems, the leaching concentration of copper ions fell greatly from 179.4 to $6.5 \mathrm{mg} \mathrm{L}^{-1}$. Because of the mentioned complications, it was indicated that the behavior mechanisms of copper ions under microwave could not be explained, and it would be continued to be searched in the next studies. In a different study where the stabilization of sludge was tested by using sodium sulfide and sodium sulfate, researchers reported that the used additional materials had positive effects on stabilization with microwave (Chen et al. 2007). It was also stated in various other studies that sulfide and phosphate anions constitute low solubility stable forms by reacting with heavy metals (Nzihou and Sharrock 2002). It was also indicated that increase in the temperature causes an increase in the efficiency of stabilization, and when compared to the conventional heating methods, heating with microwave is a quite effective method. In the system where sodium sulfate was used, on the top filtrate, the copper amount fell from 90.2 to $8.09 \mathrm{mg} \mathrm{L}^{-1}$, while this amount decreased to $16.3 \mathrm{mg} \mathrm{L}^{-1}$ in the system where sodium phosphate was used. In the light of these results, it was 
reported that through the use of microwave and additional materials, the efficiency of stabilization could be increased (Chen et al. 2007).

In the study, the efficiency of stabilization of metallic forms, which emerged as a result of pyrolysis process applied together with microwave and caused sludge to turn into a hazardous waste, was analyzed. While, in the literature, there are only limited studies conducted with specific metals, in this study different forms existing in the same environment, such as $\mathrm{CaO}, \mathrm{Fe}_{2} \mathrm{O}_{3}, \mathrm{ZnO}, \mathrm{NiO}, \mathrm{CuO}, \mathrm{Cr}_{2} \mathrm{O}_{3}$, $\mathrm{MnO}$, and $\mathrm{SnO}_{2}$, were monitored.

\section{Study area}

The experimental approach was implemented in the research laboratories of Environmental Engineering Department at Istanbul University in 2014. The galvanic samples were collected from a galvano-technic processing industry located in Istanbul/Turkey.

\section{Materials and methods}

The sludge samples with which stabilization studies were conducted were taken from filter press outlet of the common wastewater treatment facility that belongs to organized galvano-technic industrial zone, which operates in Istanbul/Turkey. Samples were presented with "G" code.

\section{Material}

Chemical properties of sludge sample are given in tables below. Tables 1 and 2 show chemical properties of raw treatment sludge sample.

\section{Experimental}

From the taken treatment sludge, 11 samples-each was $50 \mathrm{~g}$-were prepared, and first they were dehydrated for

Table 1 X-ray fluorescence (XRF) results of raw treatment sludge

\begin{tabular}{lllllllll}
\hline Code & \multicolumn{2}{l}{ XRF, wt $\%$} \\
\cline { 2 - 8 } & $\mathrm{CaO}$ & $\mathrm{Fe}_{2} \mathrm{O}_{3}$ & $\mathrm{ZnO}$ & $\mathrm{NiO}$ & $\mathrm{CuO}$ & $\mathrm{Cr}_{2} \mathrm{O}_{3}$ & $\mathrm{MnO}$ & $\mathrm{SnO}_{2}$ \\
\hline $\mathrm{G} 0$ & 22.74 & 11.13 & 7.87 & 6.97 & 3.55 & 2.88 & 0.27 & 0.27
\end{tabular}

Table 2 Chemical properties of raw treatment sludge

\begin{tabular}{llllll}
\hline Code & \multicolumn{4}{l}{ Properties, wt $\%$} \\
\cline { 2 - 6 } & Moisture & Dry matter & Volatile $^{\mathrm{a}}$ & $\mathrm{Ash}^{\mathrm{a}}$ & $\mathrm{FC}^{\mathrm{a}, \mathrm{b}}$ \\
\hline G0 & 57 & 43 & 64 & 30 & 6 \\
\hline
\end{tabular}

$F C$ Fixed carbon

${ }^{a}$ Dry basis

${ }^{b}$ By difference
$24 \mathrm{~h}$ at $105^{\circ} \mathrm{C}$ in a Lenton Eurotherm-branded dryingoven and then reduced to 1-2 mm through sifting. "G0"coded raw sample was sent to the laboratory for X-ray fluorescence (XRF) analysis. On the other hand, "G1"coded sample was directly applied pyrolysis for $1 \mathrm{~h}$ at $600{ }^{\circ} \mathrm{C}$, together with $1 \mathrm{~L} \mathrm{~min}^{-1} \mathrm{~N}_{2}$ gas, without any pretreatment. In the experiments, the duration of pyrolysis was determined as $1 \mathrm{~h}$. Temperature control was provided through fixed-bed updraft stainless steel reactor, which is $7 \mathrm{~cm}$ in diameter, and impermeability was provided through pure graphite and graphite-lead spiral gaskets. In the system, while the pyrolysis experiments were being conducted, condensable volatile organics, generated within the synthesis gas, were collected through cooling pipes and weighed. The synthesis gas that transfers without condensation was continually tied to gas analysis device and $\mathrm{CO}$, $\mathrm{CO}_{2}, \mathrm{H}_{2}, \mathrm{CH}_{4}$, and $\mathrm{O}_{2}$ amounts were weighed in volumetric percentage.

In the study, a five-staged microwave oven that has maximum $900-\mathrm{W}$ power and $2.45-\mathrm{GHz}$ frequency was used for the preheat process. Performed in different operation periods as being 3, 5, and $10 \mathrm{~min}$, and in different power frequencies as being 360, 600, and $900 \mathrm{~W}$, the optimum conditions were determined, and internal temperatures of the samples were measured and recorded. In total, $900 \mathrm{~W}$ was adjusted as the maximum power to be able to assess the effect of high microwave power during $10 \mathrm{~min}$ on metal stabilization. In the literature, in the studies carried out for sludge stabilization, it has been reported that $600-\mathrm{W}$ power and 5-min radiation period have been frequently used (Hsieh et al. 2007; Chen et al. 2005). In Table 3, the conditions of microwave pre-treatment are given, and in Fig. 1, the schematic display of pyrolysis mechanism is given.

\section{Analytical methods}

Solid material analyses were made in Istanbul University Advanced Analysis Laboratories, via PANalytical Axiosbranded XRF device of the institution. In addition,

Table 3 Microwave pre-treatment conditions

\begin{tabular}{llc}
\hline Code & Mw power $(\mathrm{W})$ & Mw time (min) \\
\hline G2 & 360 & 3 \\
G3 & 360 & 5 \\
G4 & 360 & 10 \\
G5 & 600 & 3 \\
G6 & 600 & 5 \\
G7 & 600 & 10 \\
G8 & 900 & 3 \\
G9 & 900 & 5 \\
G10 & 900 & 10 \\
\hline
\end{tabular}




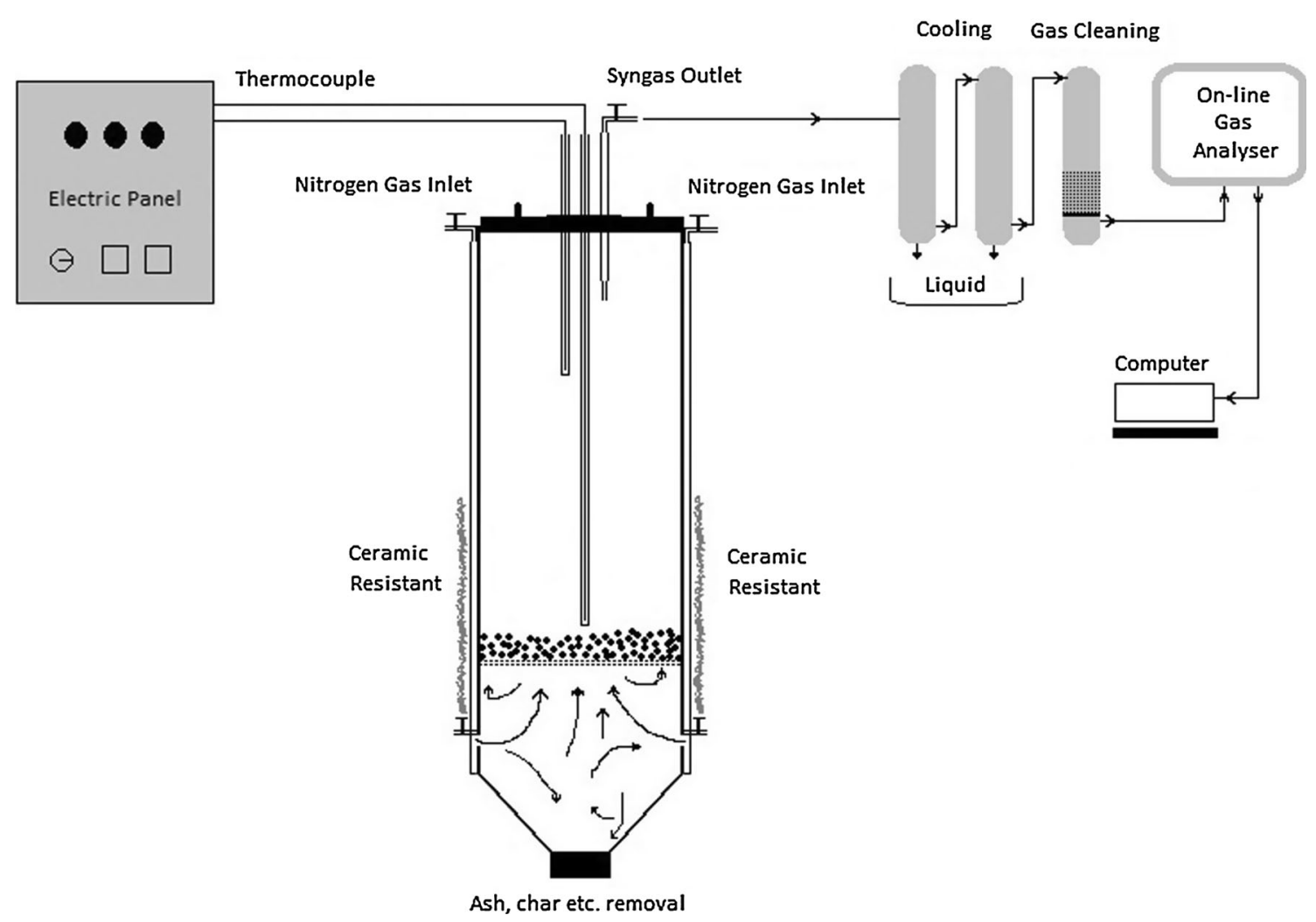

Fig. 1 Schematic diagram of the reactor

moisture, ash, dry matter, combustion loss, and carbon analyses were made in accordance with Standard Methods, 21th Edition.

It was decided that $\mathrm{CaO}$ metal oxide should be mapped as elemental since it was highly found in the sludge sample. The mapping was performed via FEI Quanta 450 model scanning electron microscopy/energy-dispersive X-ray spectroscopy (SEM-EDS) device, which belongs to Istanbul University, Department of Chemical Engineering, Process and Reactor Designing Department.

Although the aim and topic of the conducted study is not about gas output, measurement of synthetic gas was made and the content of gas was analyzed via ABB-branded AO2020 model online gas analyzer; and $\mathrm{CO}, \mathrm{CO}_{2}, \mathrm{H}_{2}$, $\mathrm{CH}_{4}, \mathrm{O}_{2}$ amounts were weighed in volumetric percentage.

\section{Results and discussion}

\section{Experimental}

Measurements of the acquired material obtained from the raw galvanic sludge, which was applied to pyrolysis process without pre-treatment, are given in Table 4, and the XRF analysis results of the solid form are given in Table 5.
Table 4 Mass conversions after pyrolysis of raw sludge

\begin{tabular}{lllll}
\hline Code & Initial $(\mathrm{g})$ & Solid $(\mathrm{g})$ & Liquid $(\mathrm{g})$ & Syngas $(\mathrm{g})$ \\
\hline $\mathrm{G} 1$ & 50 & 39 & 6 & 5 \\
\hline
\end{tabular}

Table 5 XRF results of char residue after pyrolysis of raw sludge

\begin{tabular}{lllllllll}
\hline Code & \multicolumn{2}{l}{ XRF results, wt\% } \\
\cline { 2 - 9 } & $\mathrm{CaO}$ & $\mathrm{Fe}_{2} \mathrm{O}_{3}$ & $\mathrm{ZnO}$ & $\mathrm{NiO}$ & $\mathrm{CuO}$ & $\mathrm{Cr}_{2} \mathrm{O}_{3}$ & $\mathrm{MnO}$ & $\mathrm{SnO}_{2}$ \\
\hline $\mathrm{G} 1$ & 19.86 & 10.89 & 7.25 & 6.46 & 3.22 & 3.03 & 0.26 & 0.28
\end{tabular}

The change in the amount of solid material acquired as a result of microwave pre-treatment (Mw) applied to galvanic sludge samples in accordance with the specified conditions, and the molar transformation after pyrolysis with microwave pre-treatment (MwP) is given in Table 6.

When the solid material amount, occurred as a result of processes applied to galvanic sludge samples, was analyzed, depending on the duration and power of the microwave pre-treatment, with the increasing power in terms of mass, a decrease based upon moisture loss was observed. As a result of the pyrolysis process, it was observed that the formation of liquid and gas forms was 
Table 6 Mass conversions after $\mathrm{Mw}$ and $\mathrm{MwP}$ processes
Table 7 XRF results of char obtained from MwP process

\begin{tabular}{llllll}
\hline Code & Initial $(\mathrm{g})$ & Mw solid $(\mathrm{g})$ & MwP solid $(\mathrm{g})$ & MwP liquid $(\mathrm{g})$ & MwP syngas $(\mathrm{g})$ \\
\hline G2 $(3 \mathrm{~min}, 360 \mathrm{~W})$ & 50 & 48.04 & 36.78 & 9.17 & 2.09 \\
G3 $(5 \mathrm{~min}, 360 \mathrm{~W})$ & 50 & 43.07 & 36.46 & 4.75 & 1.86 \\
G4 $(10 \mathrm{~min}, 360 \mathrm{~W})$ & 50 & 41.28 & 36.09 & 3.42 & 1.77 \\
G5 (3 min, 600 W) & 50 & 46.65 & 36.10 & 7.16 & 3.39 \\
G6 (5 min, 600 W) & 50 & 42.33 & 35.74 & 5.08 & 1.51 \\
G7 (10 min, 600 W) & 50 & 40.89 & 35.49 & 2.86 & 2.54 \\
G8 (3 min, 900 W) & 50 & 45.11 & 35.81 & 5.88 & 3.42 \\
G9 (5 min, 900 W) & 50 & 41.80 & 35.39 & 4.25 & 2.16 \\
G10 (10 min, 900 W) & 50 & 39.56 & 34.58 & 2.34 & 2.64
\end{tabular}

\begin{tabular}{lllllllll}
\hline Code & \multicolumn{7}{l}{$\mathrm{XRF}, \mathrm{wt} \%$} \\
\cline { 2 - 8 } & $\mathrm{CaO}$ & $\mathrm{Fe}_{2} \mathrm{O}_{3}$ & $\mathrm{ZnO}$ & $\mathrm{Cr}_{2} \mathrm{O}_{3}$ & $\mathrm{NiO}$ & $\mathrm{CuO}$ & $\mathrm{MnO}$ & $\mathrm{SnO}_{2}$ \\
\hline $\mathrm{G} 2(3 \mathrm{~min}, 360 \mathrm{~W})$ & 22.43 & 17.92 & 6.98 & 5.87 & 4.91 & 2.63 & 0.23 & 0.11 \\
$\mathrm{G} 3(5 \mathrm{~min}, 360 \mathrm{~W})$ & 22.50 & 17.85 & 7.03 & 5.81 & 4.92 & 2.60 & 0.23 & 0.12 \\
$\mathrm{G} 4(10 \mathrm{~min}, 360 \mathrm{~W})$ & 22.55 & 17.89 & 6.96 & 5.84 & 4.87 & 2.50 & 0.19 & 0.10 \\
G5 (3 min, 600 W) & 22.70 & 17.69 & 6.94 & 5.81 & 4.84 & 2.65 & 0.23 & 0.10 \\
G6 (5 min, 600 W) & 22.47 & 16.93 & 6.71 & 5.63 & 4.65 & 2.49 & 0.22 & 0.15 \\
G7 (10 min, 600 W) & 23.14 & 17.40 & 6.71 & 5.83 & 4.69 & 2.44 & 0.20 & 0.14 \\
G8 (3 min, 900 W) & 22.91 & 18.30 & 7.13 & 5.92 & 5.06 & 2.70 & 0.22 & 0.11 \\
G9 (5 min, 900 W) & 23.02 & 17.81 & 6.97 & 5.75 & 4.86 & 2.66 & 0.20 & 0.16 \\
G10 (10 min, 900 W) & 23.56 & 17.64 & 7.02 & 5.80 & 4.88 & 2.53 & 0.20 & 0.11 \\
\hline
\end{tabular}

limited because of the sample characteristic. In Table 7, the $\mathrm{XRF}$ analysis results of the sample samples are given.

In Fig. 2, graphics were illustrated for the three forms that were identified as a result of the pyrolysis process and the pre-treatments, applied under variable duration and microwave power.

As a result of the gas analysis measured in the pyrolysis experiments, it was identified that since carbon content of the sample was very low, among the gas forms, only carbon dioxide arose; it was stated that this gas reached to the maximum level in the first 10-20 min of the experiment, and in time it decreased. It was also stated that the calorific value of the acquired syngas was low, as it had been expected.

\section{Scanning electron microscopy (SEM) results}

Galvanic sludge sample was scanned with scanning electron microscope through $\times 5000$ zoom. Several types of residue observed on the stub. Scanning was used for all metals; however, only for calcium, the quality scans could be obtained. Calcium is the most densely found metal in the raw sludge. Figure 3 shows SEM display of raw treatment sludge and $\mathrm{Ca}$ element mapping.

$\times 5000$ zoomed SEM analysis displays of "G1" sample, which was applied pyrolysis without microwave pretreatment, are presented in Fig. 4.
As it can be seen, Ca element is densely found in solid residue after pyrolysis. After the experiments, under relatively more fertile conditions (600 W, $5 \mathrm{~min})$, MwP process was applied to "G6"-coded study, and $\times 5000$ zoomed SEM analysis results of the solid product acquired from this process are given in Fig. 5.

It is observed in Fig. 5 that Ca element was absorbed in the porous structure of the stub after microwave application.

\section{Conclusion}

Treatment sludge is the sludge resulting from the treatment of wastewater that emerged as a result of the galvanization process, and its metal content is dense. To eliminate hazardous galvanic sludge, the necessary precautions with regard to the specified regulations should be taken, and by this way, the appropriate elimination of the sludge should be provided.

When the above given results are analyzed, it is observed that the increase in the microwave power has no significant effect on the solid form stabilization of $\mathrm{Ca}, \mathrm{Fe}$, and $\mathrm{Cr}$ compounds found in the galvanic sludge. Only with the increase in the microwave power, a small rise is seen in the stabilization percentage. When the conventional 

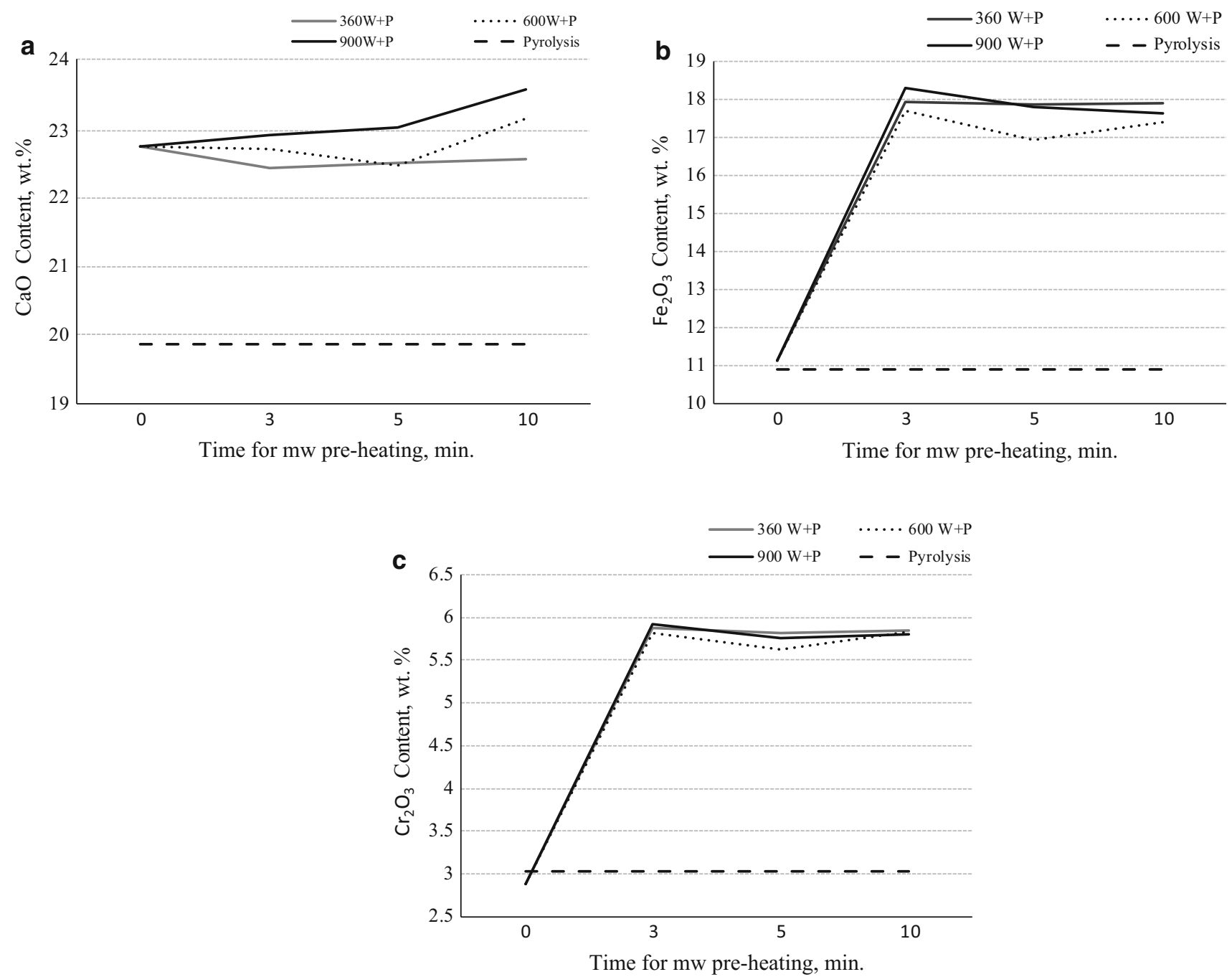

Fig. 2 Distribution of calcium, iron, and chromium by time and process applied, a $\mathrm{CaO}$ wt $\%, \mathbf{b} \mathrm{Fe}_{2} \mathrm{O}_{3}$ wt $\%$, $\mathbf{c} \mathrm{Cr}_{2} \mathrm{O}_{3}$ wt $\%$

Fig. 3 SEM display of "G0" raw treatment sludge sample (a) and the mapping of " $\mathrm{Ca}$ " element (b)
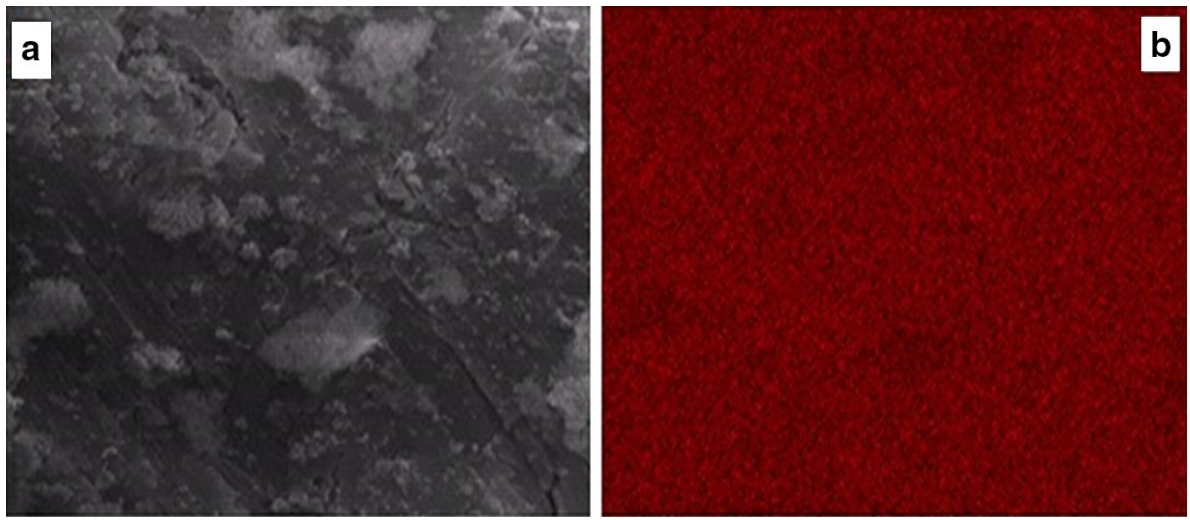

pyrolysis process and microwave-supported trials are compared, it is clearly determined that within the solid form for $\mathrm{Ca}, \mathrm{Fe}$, and $\mathrm{Cr}$ compounds in the galvanic sludge, stabilization is provided. It is thought that this situation occurs depending on the high-energy radiation and sintering, applied onto the material with microwave.

It is also determined that the increasing duration of microwave radiation has no significant effects on metal 
Fig. 4 SEM display of "G1" sample solid product (a) and the mapping of Ca element (b)
Fig. 5 SEM display of "G6" sample solid product (a) and the mapping of $\mathrm{Ca}$ element (b)
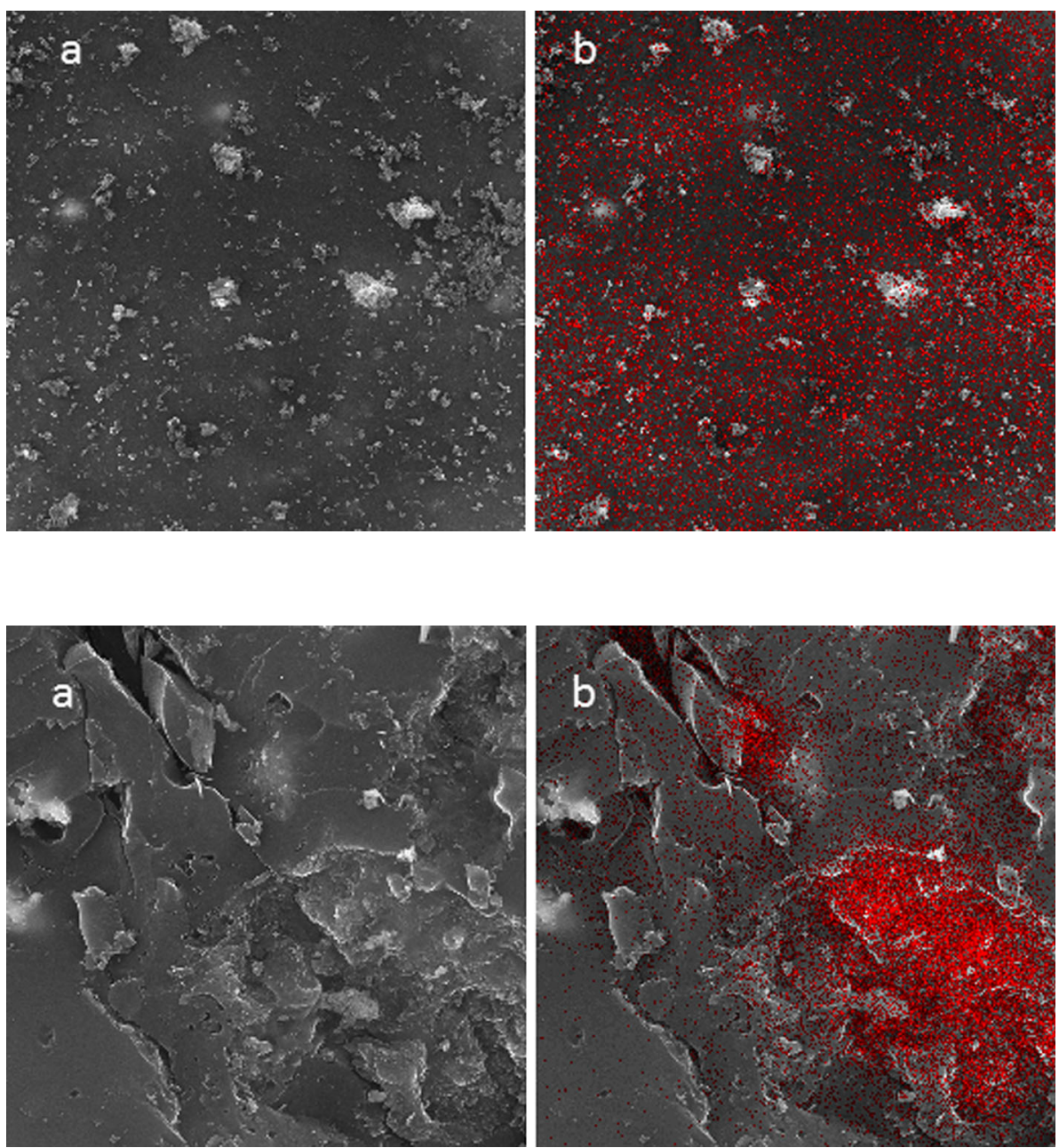

stabilization. Although some increases and decreases are identified for some metals, it is observed that these differences are low in terms of molar percentage. For $\mathrm{Cr}_{2} \mathrm{O}_{3}$, in a $600-\mathrm{W}$ microwave application for 3-, 5-, and 10-min durations, the molar percentages hold in the solid form is respectively weighed as 5.63, 5.83, and $5.92 \mathrm{wt} \%$. Although the results show a little increase, this percentage increase is quite limited.

It is observed that as microwave power and the pretreatment duration in microwave increase, formation of the liquid product resulted from the pyrolysis decreases, although this decrease is limited.

When the conducted SEM analyses are examined, it is observed that wastewater treatment sludge has an amorphous structure. With the aim of exemplifying the monitoring of the behaviors of metal compounds, Ca metal, the most densely found element within the sludge in SEM analysis, is mapped. The $\mathrm{Ca}$ amount found in raw sample decreases when pyrolysis is directly practiced, and increases after the application of the pyrolysis with microwave pre-treatment, and it is also determined that metal does not accumulate on flat surfaces but on surfaces where porosity shows increase.

In accordance with the aim of the study, stabilization of the volatile metal compounds in treatment sludge with microwave preheating, and the controllability of possible emission sources were analyzed. The acquired data show that a certain amount of stabilization is provided. This situation is interpreted as such that with microwave energy, glazing occurs on metal compounds, and so they are blocked through preventing the creation of volatile forms of metals.

In conclusion, it is observed that as a result of using microwave energy as a pre-treatment before pyrolysis applications, some volatile metal compounds within the wastewater treatment sludge can be restrained within solid remains. However, it will be understood in further studies whether there is an efficient application on different metals or not and whether the efficiency of stabilization can be increased or not.

Acknowledgments This study was supported with 11981 numbered project of Istanbul University Executive Secretary of Scientific Research Projects. 


\section{References}

Chen CL, Lo SL, Kuan WH, Hsieh CH (2005) Stabilization of Cu in acid-extracted industrial sludge using a microwave process. J Hazard Mater B123:256-261

Chen CL, Lo SL, Chiueh PT, Kuan WH, Hsieh CH (2007) The assistance of microwave process in sludge stabilization with sodium sulfide and sodium phosphate. J Hazard Mater 147:930-937

Chen D, Yin L, Wang H, He P (2015) Reprint of: pyrolysis technologies for municipal solid waste: a review. Waste Manage $37: 116-136$

Cieslik BM, Namiesnik J, Konieczk P (2015) Review of sewage sludge management: standards, regulations and analytical methods, a review. J Clean Prod 90:1-15

Collivignarelli MC, Castagnola F, Sordi M, Bertanza G (2015) Treatment of sewage sludge in a thermophilic membrane reactor (TMR) with alternate aeration cycles. J Environ Manage 162:132-138

Dai Q, Jiang X, Wang F, Chi Y, Yan J (2013) PCDD/Fs in wet sewage sludge pyrolysis using conventional and microwave heating. J Anal Appl Pyrol 104:280-286

Deng W, Su Y, Liu S, Shen H (2014) Microwave-assisted methane decomposition over pyrolysis residue of sewage sludge for hydrogen production. Int J Hydrogen Energ 39:9169-9179

Donaj P, Yang W, Blasiak W, Forsgren C (2010) Recycling of automobile shredder residue with a microwave pyrolysis combined with high temperature steam gasification. J Hazard Mater 182:80-89

Donaj P, Blasiaka W, Yang W, Forsgren C (2011) Conversion of microwave pyrolysed ASR's char using high temperature agents. J Hazard Mater 185:472-481

Efika EC, Onwudili JA, Williams PT (2015) Products from the high temperature pyrolysis of RDF at slow and rapid heating rates. J Anal Appl Pyrol 112:14-22

Garrido-Baserba M, Molinos-Senante M, Abelleira-Pereira JM, FdezGüelfo LA, Poch M, Hernandez-Sancho F (2015) Selecting sewage sludge treatment alternatives in modern wastewater treatment plants using environmental decision support systems. J Clean Prod 107:410-419

Hsieh CH, Loa SH, Chiueh PT, Kuan WH, Chen CL (2007) Microwave enhanced stabilization of heavy metal sludge. J Hazard Mater B139:160-166

Hui KW, Lung CC, Lien LS (2008) Application of microwave energy on the stabilization of copper containing industrial sludge. Res $\mathbf{J}$ Chem Environ 12(3):77-81
Ibanez GR, Esteban B, Ponce-Robles L, Casas JL, Agüera A, Pérez JA (2015) Fate of micropollutants during sewage sludge disintegration by low-frequency ultrasound. Chem Eng J 280:575-587

Iwasaki W (2003) A consideration of the economic efficiency of hydrogen production from biomass. Int $\mathrm{J}$ Hydrogen Energ 28:939-944

Liu X, Zheng W, Sun K, Lin C, Zhao Y (2013) Immobilization of cadmium onto activated carbon by microwave irradiation assisted with humic acid. J Taiwan Inst Chem E 44:972-976

Moon J, Mun TY, Yang W, Lee U, Hwang J, Jang E, Choi C (2015) Effects of hydrothermal treatment of sewage sludge on pyrolysis and steam gasification. Energy Convers Manage 103:401-407

Mushtaq F, Mat R, Ani FN (2014) A review on microwave assisted pyrolysis of coal and biomass for fuel production. Renew Sust Energ Rev 39:555-574

Nzihou A, Sharrock P (2002) Calcium phosphate stabilization of fly ash with chloride extraction. Waste Manage 22:235-239

Pavlik Z, Forta J, Zaleska M, Pavlikova M, Trnik A, Medved I, Keppert M, Koutsoukos PG, Cerny R (2015) Energy-efficient thermal treatment of sewage sludge for its application in blended cements. J Clean Prod. doi:10.1016/j.jclepro.2015.09.072

Semiyaga S, Okure MAE, Niwagaba CB, Katukiza AY, Kansiime F (2015) Decentralized options for faecal sludge management in urban slum areas of Sub-Saharan Africa: a review of technologies, practices and end-uses. Resour Conserv Recy. doi:10.1016/ j.resconrec.2015.09.001

Standard Methods (2005) 21st Edition, ISBN-13: 978-0875530475 ISBN-10: 0875530478

Undri A, Sacchi B, Cantisani E, Toccafondi N, Rosi L, Frediani MN, Frediani P (2013) Carbon from microwave assisted pyrolysis of waste tires. J Anal Appl Pyrol 104:396-404

Wub D, Tian Y, Wenc X, Zuo W, Liu H, Lee DJ (2015) Studies on the use of microwave for enhanced properties of glass-ceramics produced from sewage sludge pyrolysis residues (SSPR). J Taiwan Inst Chem 48:81-86

Xie Q, Peng P, Liu S, Min M, Cheng Y, Wana Y, Li Y, Lin X, Liu Y, Chen P, Ruan R (2014) Fast microwave-assisted catalytic pyrolysis of sewage sludge for bio-oil production. Bioresour Technol 172:162-168

Yang G, Zhang G, Wang H (2015) Current state of sludge production, management, treatment and disposal in China. Water Res 78:60-73

Yu Y, Yu J, Sun B, Yan Z (2014) Influence of catalyst types on the microwave-induced pyrolysis of sewage sludge. J Anal Appl Pyrol 106:86-91 